\title{
Norovirus-related chronic diarrhea in a patient treated with alemtuzumab for chronic lymphocytic leukemia
}

\author{
Anne-Marie Ronchetti ${ }^{1}$, Benoit Henry ${ }^{2}$, Katia Ambert-Balay ${ }^{3}$, Pierre Pothier ${ }^{3}$, Justine Decroocq ${ }^{1}$, Véronique Leblond ${ }^{1}$ \\ and Damien Roos-Weil ${ }^{1 *}$
}

\begin{abstract}
Background: Norovirus infection is increasingly recognized as an important cause of persistent gastroenteritis in immunocompromised hosts and can be a potential cause of morbidity in these populations.

Case presentation: Here, we report a case of norovirus-related chronic diarrhea occurring in a 62-year-old immunocompromised patient treated with alemtuzumab for chronic lymphocytic leukemia. Despite different therapeutic strategies including tapering of immunosuppressive therapy and immunoglobulin administration, diarrhea unfortunately did not resolve and lasted for a total of more than twelve weeks with prolonged norovirus fecal excretion.

Conclusions: Norovirus infection can occur in the setting of alemtuzumab treatment, even as a single agent, and should be included in the differential diagnoses of acute and chronic diarrhea in these immunocompromised patients. Although the administration of oral immunoglobulin has been described as a promising efficient therapy, this was not the case in our patient. Clinical trials are thus clearly warranted to better define risk factors and efficient therapies for norovirus infection in immunocompromised populations.
\end{abstract}

Keywords: Norovirus, Diarrhea, Immunosuppression, Alemtuzumab, Chronic lymphocytic leukemia

\section{Background}

Norovirus (NoV), a separate genus of the enteric virus family Caliciviridae, is actually recognized as the overall leading cause of acute gastro-enteritis (GE), being the first and second cause in adult and children, respectively, and accounts for more than $90 \%$ of GE outbreaks [1]. In immunocompetent individuals, symptoms usually last for a few days but recent studies have shown that $\mathrm{NoV}$ infection can be chronic and severe among vulnerable populations like solid organ and bone marrow transplantation (BMT) recipients [2-4], inherited immune deficiencies [5] or HIV infected patients [6]. Human mechanisms for protective immunity and clearance of $\mathrm{NoV}$ are not well defined. Although its precise mechanism is still unclear, it is hypothesized that cellular immunity plays an important

\footnotetext{
* Correspondence: damien.roos-weil@inserm.fr

${ }^{1}$ Hematology Department, Hôpital Pitié-Salpétrière, AP-HP, Université Pierre et Marie Curie Paris 06, GRC 11 (GRECHY), Paris, France

Full list of author information is available at the end of the article
}

role as suggested, for example, by the resolution of GE following the decrease of immunosuppressive therapy [3] or by the association between donor $\mathrm{T}$ cell recovery and $\mathrm{NoV}$ clearance [7] in BMT recipients.

Alemtuzumab is a humanized monoclonal IgG1 antibody directed toward the cell surface antigen CD52. It is largely used in chronic lymphoproliferative disorders like chronic lymphocytic leukemia (CLL), leading to profound $\mathrm{T}$ and $\mathrm{B}$ lymphocyte depletion and exposing patients to life-threatening opportunistic infections, particularly viruses, like CMV [8]. Although NoV infection has never been described in patients treated with alemtuzumab alone, the use of alemtuzumab in the conditioning regimen of BMT has been interestingly reported to be a potential risk factor for NoV GE in two studies $[4,9]$.

$\mathrm{NoV}$ treatment in immunocompromised patients is challenging and mainly supportive as no specific therapy actually exists. Different strategies have been tested, from the adjustment of immunosuppressive treatment to the 
use of oral immunoglobulin (Ig) or antiviral drugs, but with controversial results [2]. We report here a case of NoV-related chronic diarrhea, in an immunocompromised patient treated with alemtuzumab, which did not respond to Ig administrations.

\section{Case presentation}

A French 62-year-old man was hospitalized in our institution for severe invasive aspergillosis. His medical history was remarkable for chronic lymphocytic leukemia (CLL), diagnosed in 1998 and first requiring therapy in 2006. From 2006 to 2010, our patient received several lines of treatment comprising polychemotherapies with anthracyclines (in 2006), purines analogs (fludarabine) (in 2007), alkylating agents (cyclophosphamide) (in 2010), high dose corticosteroids and immunotherapy (rituximab) (in 2006, 2007 and 2010), alternatively or in combination. Last relapse of CLL occurred in December 2011 and motivated a new therapeutic sequence with alemtuzumab and dexamethasone. In January 2012, three weeks after the initiation of alemtuzumab, he developed fever, cough and subacute vision loss of the left eye, revealing a multi-organ aspergillosis that involved lung, eyes and also brain. Apart from this severe infectious complication that required prolonged antifungal therapy with voriconazole, the clinical evolution during hospitalization was marked by the persistence of intermittent fever and the progressive onset of fluctuating watery diarrhea, which started six weeks after the first alemtuzumab dose (February 2012). Diarrhea lasted for a total of more than twelve weeks. Diarrheal stools were profuse but contained neither blood nor mucus. The patient had no concomitant abdominal pain, vomiting or myalgia. He had no recent travel history, no family history of vomiting or diarrhea and there was no argument for any nosocomial outbreak at this time in our department. All potential medications that can induce diarrhea, including voriconazole and alemtuzumab, were withdrawn but without efficacy. Empiric antibiotic therapies (successively ceftriaxone, ciprofloxacine, metronidazole and piperacillin/tazobactam) were also unsuccessful. Of note, repeated microbiological stool examinations, including cultures and assays for pathogenic bacteria (C. difficile, Camplyobacter spp., Salmonella spp., and Yersinia spp.) and standard detection of protozoans (including searches for Microsporidium sp., Cryptosporidium sp., Isospora sp. and Giardia lamblia), were negative. Serum cytomegalovirus (CMV) and adenovirus polymerase chain reactions (PCRs), stool rotavirus and adenovirus PCRs were also negative. Colonoscopy did not find any ulcerative lesion and pathologic examination of colonic biopsies any cytopathic effect. There was also no argument for aspergillosis involvement in the gastrointestinal tract. The persistence of diarrhea and the negativity of standard pathogenic microorganisms responsible for GE finally raised the possibility of NoV infection. Fecal NoV reverse transcriptase (RT)-PCR was positive for recombinant genogroup II, genotype 7 and genotype 6 (GII.7/II.6). Sequencing of the ORF1/ORF2 junction, as described previously [10], excluded the possibility of co-infection of two NoV genotypes. More, NoV viral loads have been retrospectively calculated for four fecal samples (see Figure 1). Values ranged from $2.4 \times 10^{8}$ copies/g up to $2.3 \times 10^{9}$ copies/g of stool. Our results are concordant with reported values in previous studies which ranged from $10^{3}$ to $10^{11}$ copies/g of stool, with median/mean values between $10^{7}$ and $10^{8}$ copies/g $[11,12]$ and consistent with prolonged viral excretion.

At that time, the Ig level was low (IgG $5.6 \mathrm{~g} / \mathrm{L}$ (normal: 6.7-12.5 g/L); IgA $0.25 \mathrm{~g} / \mathrm{L}$ (normal: $1.04-3.33 \mathrm{~g} / \mathrm{L}$ ), IgM $0.57 \mathrm{~g} / \mathrm{L}$ (normal 0.4-2.3 g/L)) and the lymphocyte count show profound $\mathrm{T} \mathrm{CD} 4$ and $\mathrm{CD} 8$ depletion (CD4+ $0.03 \mathrm{G} / \mathrm{L}, \mathrm{CD} 8+0.05 \mathrm{G} / \mathrm{L}, \mathrm{B}$ cell count of $0.9 \mathrm{G} / \mathrm{L}$ ). Of note, two months before alemtuzumab treatment in October 2011, T CD4+/CD8+ counts were only slightly decreased at, respectively, 0.4 and $0.3 \mathrm{G} / \mathrm{L}$. As the administration of parenteral or oral Ig has been suggested to be of potential interest in NoV GE after transplantation [11,13-15], we tried these two therapeutic options but without success (see Figure 1). First, intravenous Ig was administrated at the dose of $0.5 \mathrm{~g} / \mathrm{kg}$ for a single day, ten weeks after the beginning of alemtuzumab and four weeks after the diarrhea onset. Two weeks later, facing up to the persistence of diarrhea, we instilled Ig by oral route through a nasogastric tube at the same total dose but fractioned in four doses, every six hours for one day. Profuse diarrhea persisted and five further fecal NoV RT-PCRs were still positive for NoV GII.7/II.6 in a time period of eight weeks. Finally, evolution was fatal due to uncontrolled E. Coli bacteriemia.

\section{Discussion}

Noroviruses have been identified as an important cause of chronic diarrhea in immunocompromised hosts. Although there is growing number of case reports, it has never been described after the use of alemtuzumab as a single agent. Alemtuzumab is an anti-CD52 monoclonal antibody, which is used in CLL patients who failed fludarabine therapy and sometimes in frontline therapy in case of high-risk cytogenetic abnormalities. It has also been used in other circumstances, such as multiple sclerosis, or organ transplant rejection. The CD52 antigen is present on the surface of T, B and NK lymphocytes, and also on macrophages and dendritic cells. Alemtuzumab is a potent immunosuppressive therapy that can lead to a wide variety of severe infectious complications, especially viral and bacterial infections [15]. In patients receiving alemtuzumab, the lymphocytic depletion is estimated in median at 5 years for the CD4+ 


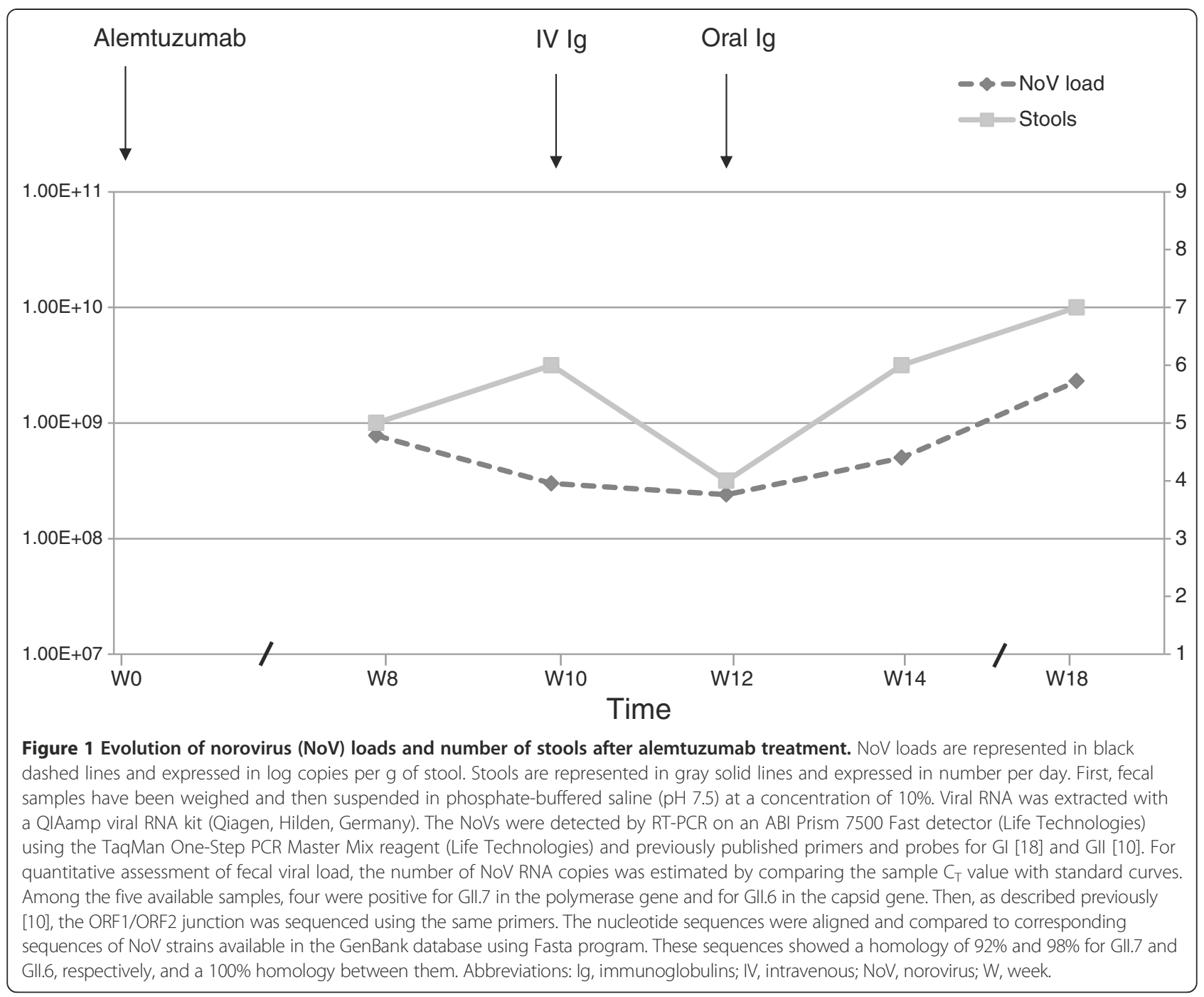

and 3 years for the CD8+ fraction [8]. In the case of our patient, the persistent NoV infection [15] despite the tapering of alemtuzumab also illustrates the very long lasting lymphocyte depletion due to this molecule, making a rapid diagnosis of infectious complications due to alemtuzumab more suitable. Although its precise role could not be certain in our observation, some arguments plead for the potential involvement of alemtuzumab in the onset of NoV infection. First, NoV diarrhea began six weeks after initiation of alemtuzumab, while the last immunosuppressive therapies (rituximab plus cyclophosphamide) have been administrated more than a year ago. Second, alemtuzumab was in a large extent responsible for the profound T-cell depletion as T-cell counts were near normal before its start. Moreover, as described above, the use of alemtuzumab is associated with severe infectious complications and has been recognized as a potential risk factor for NoV GE in allografted children when used in the conditioning regimen [9]. NoV-related chronic diarrhea has also already been reported in the setting of hypogammaglobulinemia and after immunotherapy as it has been described in a CLL patient treated with rituximab [16].

Despite different therapeutic strategies, diarrhea did not resolve in the case of our patient and NoV viral loads in fecal samples remained positive. The most promising approach reported in the literature is the use of enteral Ig as it has been described successful in four immunocompromised patients: two children with small bowel transplantation [13] and two adults, one with cardiac [17] and the other with renal transplantation [11]. The failure of this strategy in our patient could be due to the profound level of immunosuppression and/or the mode of Ig administration (rhythm, period) although we administrated the same total dose as in reported successful experiences. 


\section{Conclusions}

NoV treatment in immunocompromised patients is challenging as no specific antiviral agent actually exists and as the tapering of immunosuppressive drugs is not always possible. Vaccine research is ongoing, but no vaccine is currently available. Although parenteral and oral Ig administrations have been reported to be efficient, it was not the case in our patient. Profound T cell depletion and hypogammaglobulinemia may explain this failure of NoV clearance. Given the prolonged survival of patients with hematological malignancies and the increasing use of immunotherapies, it is likely that there will be more reports of NoV infections. NoV should be included in the differential diagnoses of acute and chronic diarrhea in immunocompromised patients and clinical trials should also be developed to define risk factors and efficient therapies.

\section{Consent}

Written informed consent was obtained from the family of the patient for publication of this Case report. A copy of the written consent is available for review by the Editor of this journal.

\section{Competing interests}

The authors declare that they have no competing interests.

\section{Authors' contributions}

AMR and DRW took care of the patient, collected and analyzed data and wrote the manuscript. BH, JD and VL took care of the patient and critically revised the manuscript. KAB and PP performed the molecular genetic studies and critically revised the manuscript. All authors read and approved the final manuscript.

\section{Acknowledgements}

The authors thank all clinicians and nurses who took care of the patient.

\section{Author details}

Hematology Department, Hôpital Pitié-Salpétrière, AP-HP, Université Pierre et Marie Curie Paris 06, GRC 11 (GRECHY), Paris, France. ${ }^{2}$ Tropical and Infectious Diseases Department, Hôpital Pitié-Salpétrière, AP-HP, Université Pierre et Marie Curie, Paris, France. ${ }^{3}$ Centre National de Référence des Virus Entériques, $\mathrm{CHU}$ de Dijon, Dijon, France.

Received: 28 December 2013 Accepted: 25 April 2014

Published: 6 May 2014

\section{References}

1. Glass RI, Parashar UD, Estes MK: Norovirus gastroenteritis. N Engl J Med 2009, 361(18):1776-1785.

2. Bok K, Green KY: Norovirus gastroenteritis in immunocompromised patients. N Engl J Med 2012, 367(22):2126-2132.

3. Roos-Weil D, Ambert-Balay K, Lanternier F, Mamzer-Bruneel MF, Nochy D, Pothier P, Avettand-Fenoel V, Anglicheau D, Snanoudj R, Bererhi L, Thervet E, Lecuit M, Legendre C, Lortholary O, Zuber J: Impact of norovirus/sapovirus-related diarrhea in renal transplant recipients hospitalized for diarrhea. Transplantation 2011, 92(1):61-69.

4. Roddie C, Paul JP, Benjamin R, Gallimore Cl, Xerry J, Gray JJ, Peggs KS, Morris EC, Thomson KJ, Ward KN: Allogeneic hematopoietic stem cell transplantation and norovirus gastroenteritis: a previously unrecognized cause of morbidity. Clin Infect Dis 2009, 49(7):1061-1068.

5. Frange P, Touzot F, Debre M, Heritier S, Leruez-Ville M, Cros G, Rouzioux C, Blanche S, Fischer A, Avettand-Fenoel V: Prevalence and clinical impact of norovirus fecal shedding in children with inherited immune deficiencies. J Infect Dis 2012, 206(8):1269-1274.

6. Wingfield T, Gallimore Cl, Xerry J, Gray JJ, Klapper P, Guiver M, Blanchard TJ: Chronic norovirus infection in an HIV-positive patient with persistent diarrhoea: a novel cause. J Clin Virol 2010, 49(3):219-222.

7. Saif MA, Bonney DK, Bigger B, Forsythe L, Williams N, Page J, Babiker ZO, Guiver M, Turner AJ, Hughes S, Wynn RF: Chronic norovirus infection in pediatric hematopoietic stem cell transplant recipients: a cause of prolonged intestinal failure requiring intensive nutritional support. Pediatr Transplant 2011, 15(5):505-509.

8. Elter T, Vehreschild JJ, Gribben J, Cornely OA, Engert A, Hallek M: Management of infections in patients with chronic lymphocytic leukemia treated with alemtuzumab. Ann Hematol 2009, 88(2):121-132.

9. Robles JD, Cheuk DK, Ha SY, Chiang AK, Chan GC: Norovirus infection in pediatric hematopoietic stem cell transplantation recipients: incidence, risk factors, and outcome. Biol Blood Marrow Transplant 2012 18(12):1883-1889.

10. Sdiri-Loulizi K, Ambert-Balay K, Gharbi-Khelifi H, Sakly N, Hassine M, Chouchane S, Guediche MN, Pothier P, Aouni M: Molecular epidemiology of norovirus gastroenteritis investigated using samples collected from children in Tunisia during a four-year period: detection of the norovirus variant GGII.4 Hunter as early as January 2003. J Clin Microbio/ 2009, 47(2):421-429.

11. Chagla Z, Quirt J, Woodward K, Neary J, Rutherford C: Chronic norovirus infection in a transplant patient successfully treated with enterally administered immune globulin. J Clin Virol 2013, 58(1):306-308.

12. Ludwig A, Adams O, Laws HJ, Schroten H, Tenenbaum T: Quantitative detection of norovirus excretion in pediatric patients with cancer and prolonged gastroenteritis and shedding of norovirus. J Med Virol 2008, 80(8):1461-1467.

13. Florescu DF, Hermsen ED, Kwon JY, Gumeel D, Grant WJ, Mercer DF, Kalil AC: Is there a role for oral human immunoglobulin in the treatment for norovirus enteritis in immunocompromised patients? Pediatr Transplant 2011, 15(7):718-721.

14. Florescu DF, Hill LA, McCartan MA, Grant W: Two cases of Norwalk virus enteritis following small bowel transplantation treated with oral human serum immunoglobulin. Pediatr Transplant 2008, 12(3):372-375.

15. Martin SI, Marty FM, Fiumara K, Treon SP, Gribben JG, Baden LR: Infectious complications associated with alemtuzumab use for lymphoproliferative disorders. Clin Infect Dis 2006, 43(1):16-24.

16. Capizzi T, Makari-Judson G, Steingart R, Mertens WC: Chronic diarrhea associated with persistent norovirus excretion in patients with chronic lymphocytic leukemia: report of two cases. BMC Infect Dis 2011, 11:131.

17. Ebdrup L, Bottiger B, Molgaard H, Laursen AL: Devastating diarrhoea in a heart-transplanted patient. J Clin Virol 2011, 50(4):263-265.

18. Lyman WH, Walsh JF, Kotch JB, Weber DJ, Gunn E, Vinje J: Prospective study of etiologic agents of acute gastroenteritis outbreaks in child care centers. J Pediatr 2009, 154(2):253-257.

doi:10.1186/1471-2334-14-239

Cite this article as: Ronchetti et al:: Norovirus-related chronic diarrhea in a patient treated with alemtuzumab for chronic lymphocytic leukemia. BMC Infectious Diseases 2014 14:239.

\section{Submit your next manuscript to BioMed Central and take full advantage of:}

- Convenient online submission

- Thorough peer review

- No space constraints or color figure charges

- Immediate publication on acceptance

- Inclusion in PubMed, CAS, Scopus and Google Scholar

- Research which is freely available for redistribution 